\title{
THE STRATEGY OF EMPIRICAL RESEARCH AND OPTIMIZATION PROCESS
}

\author{
L.E. Brossard Perez \\ L.A.B. Cortez ${ }^{+\dagger}$ \\ J. Mesa* \\ G. Bezzon ${ }^{+}$ \\ E.Olivares Gómez ${ }^{++}$ \\ * Universidad de Oriente \\ Departamento de Ingeniería Química \\ Santiago de Cuba - Cuba \\ Email: brossard@fiq.uo.edu.cu \\ + Universidade Estadual de Campinas \\ Núcleo Interdisciplinar de Planejamento Energético (NIPE) \\ Campinas, SP - Brazil \\ Email: cortez@agr.unicamp.br \\ ${ }^{++}$Universidade Estadual de Campinas \\ Faculdade de Engenharia Agrícola-FEAGRI \\ Campinas, SP - Brazil \\ Email: egomez@ct.unicamp.br \\ † To whom correspondence should be addressed
}

\begin{abstract}
Empirical modeling is considered from the perspectives of a general scheme for the Strategy of Empirical Research and Optimization Process (SEROP). This approach intends to facilitate the understanding of the necessary steps to arrive to mathematical models able to appropriately describe the behavior of a group of controllable independent variables related to a certain response. Aspects connected with definition of the problem, variable's identification and optimization stages are discussed. As an example of SEROP application, it is presented the empirical modeling of the basic extraction of alginic acid from brown algae.
\end{abstract}

Keywords: empirical optimization, empirical research, optimization strategy. 


\section{Introduction}

The study of a technical or scientific situation, usually presents two different and, in many ways, complementary points of view. These are:

a) a generalized phenomenological description and;

b) a limited empirical modelling.

Human knowledge is continuously fed by both approaches and there are countless examples of interactions between them. When the problem is to find a proper description of a process in a short time, at low costs and with the necessary accuracy, the dilemma emerges. Although theoretical models are to be preferred, they are unfortunately not available for every new practical situation. In these cases, empirical models may be used, knowing that their results are limited to the experimental region in which they were obtained. This drawback can be of no importance if what is sought is the behavior of a particular process in a set of particular conditions. However, empirical models building has also its own rules, that should be followed in order to arrive at reliable information.

Author's own experience in the field of empirical modelling is presented in this paper as a modest contribution for better planned and interpreted experimental work.

The paper is divided in three parts:

1. the search for the optimum;

2. practical considerations;

3. illustrative example.

\section{The search for the optimum}

In a well defined problem, where responses are correctly selected and where a screening process for the reduction of the identified independent variables has been applied, a search for the optimum can be conducted. The search is limited to an experimental region in which only one stationary point should be found.

Figure 1 shows the hypothetical boundaries of an experimental region where responses are plotted as contour lines, considered factors are $\mathrm{X}_{1}$ and $\mathrm{X}_{2}$. Points I and II represented the zones where initial exploring experimental designs are carried out and Point $\mathrm{C}$ stands for the optimum (a maximum in this example).

The search is initiated somewhere inside the experimental region and each new experiment is conditioned by the obtained response of the previous one. Vector I-II shows the direction to follow until a significant decrease in response is found. Then, a readjustment of variable's levels is done in a way as to get increasing responses through the new design. 


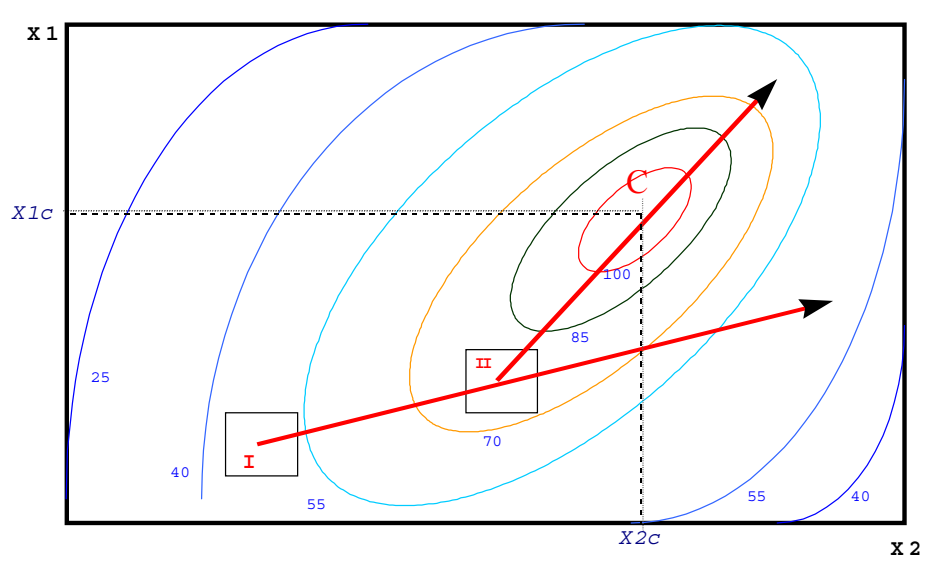

Figure 1 - Boundaries of a system with an optimum.

The procedure is repeated until curvature effects begin to be noticeable. In this point of the search, it is advisable to establish the trajectory for best performance by means of the steepest ascent method.

At the end of this last step, a new two level factorial design is conducted. The resulting model will show a big curvature effect, indicating that a second order design will describe the exact position of the stationary point. The obtained second order model is best analyzed through its response surface.

The search for the optimum is in no way a simple trial and error process and needs careful attention in every step. At this point it should be remembered that not all empirical studies have to end with an optimization process. This case takes place when the only objective is to describe conditions under which a certain process operates and there is no intention or possibility to change it.

In order to organize the different stages in the search for the optimum and also to include the simpler situation just mentioned above, a general scheme for the strategy of empirical research and optimization process (SEROP) is presented in Figure 2.

\section{Practical considerations about steps of SEROP}

Problem definition: To define the objective of an investigation, it is necessary to conduct an information searching process that will allow answering the following questions:

a) Which will be the responses to be studied and which is their hierarchy order?

It is important to establish a hierarchical order when more than one answer is selected, because they will be affected by the same factors, making it frequently impossible to find a combination of the given factors that optimizes all answers at the same time.

b) Which are the independent factors that may affect the answers?

The Larger the number of independent factors, the larger the number of experiments. The efficiency in this step will be strongly related to the investigator's selection capacity. 


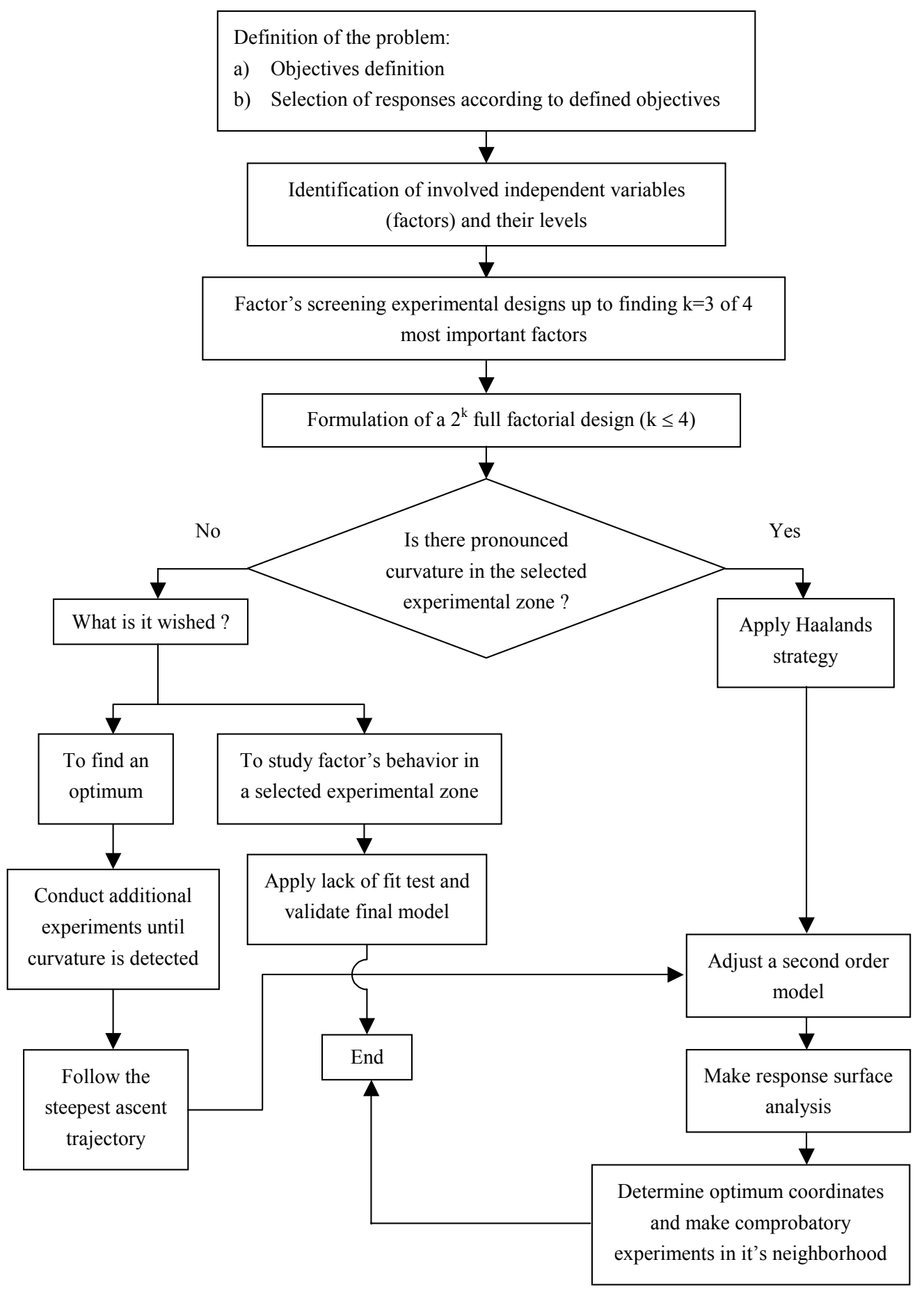

Figure 2 - Scheme showing the Strategy of Empirical Research and Optimization Process (SEROP) 


\subsection{Selection of the experimental zone under study}

The space occupied by the experiment will be determined by the separation that exists between the higher and lower levels of each factor.

1. if the levels are chosen too closely, it is possible that the response variation (Y) is not observed in the experiment or may have the order of magnitude of the stochastic fluctuations, and therefore the model will be $\mathrm{Y}=$ constant. (Figure 3 , $\mathrm{a} \leq \mathrm{X}_{\mathrm{i}} \leq \mathrm{b}$ )

2. if the levels are chosen too for apart, two mistakes may be made. (Figure 3, $a \leq X_{i} \leq d$ )

- The points "a" and "d" may be found on both sides of a maximum or a minimum and the difference between the $\mathrm{Y}$ value results may be impossible to be observed.

- The experimental errors made at different points of the region being significantly distinct, indicating in this case a lack of variance homogeneity and therefore the utilized parametric tests, for example t and F, would not be powerful enough, because they are based on the assumption that variance homogeneity exists, among other conditions.

The interval (Figure 3, a $\leq X_{i} \leq \mathrm{c}$ ) gives more reliable results, a since it contains relevant changes in the response. Naturally, before conducting the experiments, these situations are unknown, therefore the initial selection of values of the operating variables will be affected by Guerra Debén \& Sevilla (1988):

a) the historical knowledge of the system under study;

b) the available theory;

c) the existence of exploratory experiments;

d) the luck factor.

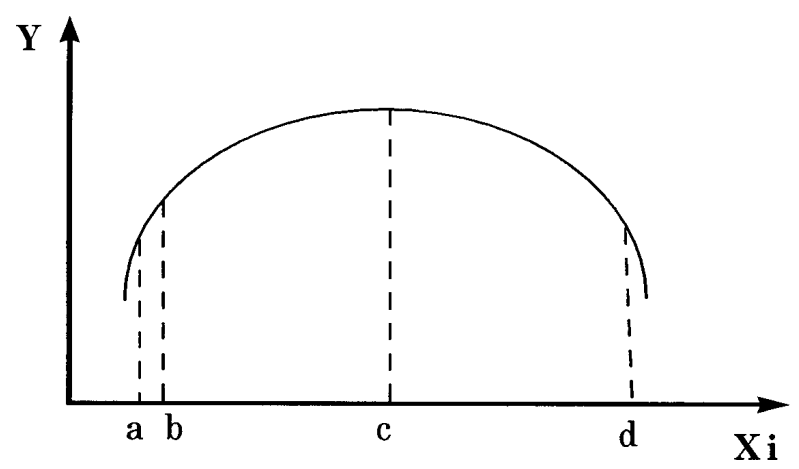

Figure 3 - Behavior of response $\mathrm{Y}$ when the level of the $\mathrm{X}_{\mathrm{i}}$ factor is varied

\subsection{The screening of independent variables (Sutton, 1997; Box et al., 1993; and Barros Neto et al., 1995)}

To avoid selecting a factor that carries little or no significance use should be made of known screening techniques (Sutton, 1997; Box et al., 1993; and Barros Neto et al., 1995). It should be borne in mind that initially identified factors must be reduced in number in order to follow an optimization strategy. 
If a factor of strong influence over the response, is not controlled, it won't be possible to obtain reliable results due to the large fluctuations that are to be observed in the response, and what is even worse, the noted behavior can be wrongly attributed to some of the controlled factors. It can also be the case that it is not possible to introduce changes in a known important factor. In such cases, the wisest thing to do is to control it at a definite favorable level. Thus, the obtained results are said to be conditioned or restricted by the factor.

\subsection{Formulation of a $2^{\mathrm{k}}$ full factorial design}

When screening work is finished, the number of independent variables should be around 4 or less. It is possible, however, to count with a fractioned design having also a maximum of 16 experiments in its planning. These numbers are not rigid limits and specific conditions will have the last word. Box et al. (1993) as well as Barros Neto et al. (1995) are excellent treatises in this respect.

\subsection{Curvature check}

When a supposed linear model, contains interaction's coefficients as big as or even bigger than individual factor's coefficients, the corresponding response surface will show curvature. There are cases where curvature, although present, is rather slight and the obtained model shows no lack of fit. However, if curvature is pronounced, linear models are not able to represent experimental behavior and need to be replaced by second order models.

Curvature can also be evaluated quantitatively by means of central points replicates. This will be shown in the illustrative example.

\subsection{Establishing the trajectory for best performance}

If the main objective of the research is to find either a maximum or a minimum for the studied response, several strategies are available. One, or perhaps the most known method, is the method of steepest ascent (Box et al., 1993), which makes use of a few exploratory points conducted according to a stepwise change in the levels of the involved factors. This change is determined by a reference factor, that usually is the one with the highest coefficient in the linear model.

In this way, an experimental trajectory is followed until a change is noted in the direction of response's increase. This point of rupture gives the necessary information about both sides of the noted change (possible stationary point) and allows a proper factor levels selection for a new two level factorial design. The resulting linear model will show a great curvature effect. This last obtained linear model is used at the nucleus of a second order design, which requires additional experimental points to fully describe the optimum zone.

If the search for the optimum is, by any reason, initiated very close to the stationary point, models with significant curvature effects will be obtained and the steepest ascent method looses efficiency. In those cases is better to apply the techniques recommended by Haaland (1989). 


\subsection{Second order design (Montgomery, 1991)}

Two of the most used second order designs are:

- Central composite orthogonal designs;

- Central composite rotational designs.

Both types of designs are carried out sequentially. This means that the information obtained from a full or fractional design is used in the data processing after adding new experiments according to the characteristics of each design.

\subsubsection{Central composite orthogonal designs (CCOD)}

These designs are distinguished by (see Table 1):

- having a nucleus made out of a full factorial design or a fraction of it;

- two extra runs for each factor, located at a coded $\alpha$ distance from the center of the experimental region. These are called axial points as they are at $(+) \alpha$ and $(-) \alpha$ distance from the zero point on the factors axes.

- one or more runs at the center of the design.

Table 1 - Structures of Central Composed Orthogonal Designs

\begin{tabular}{|c|c|c|c|c|c|c|}
\hline \multirow{2}{*}{$\begin{array}{l}\text { Number of } \\
\text { Factors }\end{array}$} & \multirow{2}{*}{$\begin{array}{c}\text { Design's Nucleus } \\
\text { (fraction of a full } \\
2^{\mathrm{K}} \text { design) } \\
\end{array}$} & \multicolumn{3}{|c|}{ Number of Runs } & \multirow{2}{*}{$\begin{array}{l}\text { Total } \\
\text { Runs }\end{array}$} & \multirow{2}{*}{$\begin{array}{c}\alpha \text { distance } \\
\text { for axial } \\
\text { points } \\
\end{array}$} \\
\hline & & $\begin{array}{c}\text { at the } \\
\text { nucleus }\end{array}$ & at the axis & $\begin{array}{l}\text { at the } \\
\text { center }\end{array}$ & & \\
\hline 2 & 1 & 4 & 4 & 1 & 9 & 1 \\
\hline 3 & 1 & 8 & 6 & 1 & 15 & 1.215 \\
\hline 4 & 1 & 16 & 8 & 1 & 25 & 1.414 \\
\hline 5 & $1 / 2$ & 16 & 10 & 1 & 27 & 1.547 \\
\hline
\end{tabular}

Second order CCOD have higher precision when:

- optimum finds itself in the close neighborhood of experimental zone's center. This is perfectly possible if an adequate optimization strategy (i.e. - steepest ascent method) has been followed or the investigators own experience indicates this is so;

- there are no time changes in experimental responses between first experiments (at the nucleus) and additional experiments (center and axis);

- variance is approximately the same for all experimental points located at equal distance from the center of the design.

\subsubsection{Central composite rotational designs (CCRD)}

This type of second order design assures the same standard error in predicted values for all experimental points located at the equal distance from the center of the design. Usually the precise nature of the response surface is not known before experimental work begins.

In this situation, it is highly improbable to distribute planned experimental points along maximum (minimum) surface slope in a way as having also minimum variance. This is why CCRD are very appreciated. Table 2 shows the structure of these designs. 
Table 2 - Structure of CCRD

\begin{tabular}{|c|c|c|c|c|c|c|}
\hline \multirow{2}{*}{$\begin{array}{c}\text { Number of } \\
\text { Factors }\end{array}$} & \multirow{2}{*}{$\begin{array}{l}\text { Design's nucleus } \\
\text { (fraction's of a } \\
\text { full } 2^{\mathrm{K}} \text { design) }\end{array}$} & \multicolumn{3}{|c|}{ Number of Runs } & \multirow{2}{*}{$\begin{array}{l}\text { Total } \\
\text { Runs }\end{array}$} & \multirow{2}{*}{$\begin{array}{c}\alpha \text { distance } \\
\text { for axial } \\
\text { points }\end{array}$} \\
\hline & & $\begin{array}{c}\text { at the } \\
\text { nucleus }\end{array}$ & $\begin{array}{l}\text { at the } \\
\text { axis }\end{array}$ & $\begin{array}{l}\text { at the } \\
\text { center }\end{array}$ & & \\
\hline 2 & 1 & 4 & 4 & 5 & 13 & 1.414 \\
\hline 3 & 1 & 8 & 6 & 6 & 20 & 1.682 \\
\hline 4 & 1 & 16 & 8 & 7 & 31 & 2.000 \\
\hline 5 & $1 / 2$ & 16 & 10 & 6 & 32 & 2.000 \\
\hline
\end{tabular}

\section{Example of SEROP}

\section{Alkaline extraction of alginic acid from brown algae (Mesa Pérez et al., 1998)}

Problem Definition: Brown algae, previously crushed and acidified with $\mathrm{HCl}$ solution, contains alginic acid that is intended to be extracted in the form of its sodium salt.

The final product, once purified, has many industrial applications based on the viscosity of its aqueous solutions. The research objective is to test an extraction method based on the reaction of a solution of sodium carbonate with alginic acid inside acid treated algae residues. The operation is batch wise conducted at room temperature $\left(26^{\circ} \mathrm{C}\right)$ under agitation. To evaluate if the objective is achieved, two responses are to be followed:

- yield of sodium alginate;

- viscosity of $1 \%$ aqueous solution of sodium alginate.

To be brief, only viscosity will be treated here.

\subsection{Identification of factors}

Initial acid treated algae as well as sodium carbonate solutions came from the same stock. All experiments were performed in the same reactor with the same reaction time and same operators.

A constant agitation speed was adopted throughout all experimental work. Under these conditions no screening was considered necessary and the following factors were identified together with their levels (see Table 3). Of course, this is a simplified situation. Screening work is almost always necessary when beginning to study a new problem.

Table 3 - Alkaline extraction of acid treated brown algae (identified factors, symbols, and levels)

\begin{tabular}{|c|c|c|c|c|}
\hline \multirow{2}{*}{ Factor } & \multirow{2}{*}{ Coded Symbol } & \multicolumn{3}{|c|}{ Levels (coded) } \\
\cline { 3 - 5 } & & Inferior (-1) & Central (0) & Superior (+1) \\
\hline Temperature $\left({ }^{\circ} \mathrm{C}\right)$ & $\mathrm{X}_{1}$ & 30 & 45 & 60 \\
\hline $\begin{array}{c}\mathrm{Na}_{2} \mathrm{CO}_{3} \text { mass } \\
\text { concentration }(\mathrm{g} / \mathrm{L})\end{array}$ & $\mathrm{X}_{2}$ & 0.6 & 1 & 1.4 \\
\hline Liquid-solid ratio $(\mathrm{kg} / \mathrm{kg})$ & $\mathrm{X}_{3}$ & 10 & 15 & 20 \\
\hline
\end{tabular}

Factor's levels were chosen according to literature information and researcher's own experience. 


\subsection{Formulation of a $2^{\mathrm{K}}$ full factorial design}

As $\mathrm{K}=3$, a $2^{3}=8$ experiments full factorial design is chosen.

Independent variable matrix ( $\mathrm{X}$ matrix) (includes experiment matrix), as well as response matrix ( $\mu$ matrix) are shown below:

$$
[X]=\left[\begin{array}{cccccccc}
X_{0} & X_{1} & X_{2} & X_{3} & X_{1} X_{2} & X_{1} X_{3} & X_{2} X_{3} & X_{1} X_{2} X_{3} \\
1 & -1 & -1 & -1 & +1 & +1 & +1 & -1 \\
1 & +1 & -1 & -1 & -1 & -1 & +1 & +1 \\
1 & -1 & +1 & -1 & -1 & +1 & -1 & +1 \\
1 & +1 & +1 & -1 & +1 & -1 & -1 & -1 \\
1 & -1 & -1 & +1 & +1 & -1 & -1 & +1 \\
1 & +1 & -1 & +1 & -1 & +1 & -1 & -1 \\
1 & -1 & +1 & +1 & -1 & -1 & +1 & -1 \\
1 & +1 & +1 & +1 & +1 & +1 & +1 & +1 \\
1 & 0 & 0 & 0 & 0 & 0 & 0 & 0 \\
1 & 0 & 0 & 0 & 0 & 0 & 0 & 0 \\
1 & 0 & 0 & 0 & 0 & 0 & 0 & 0
\end{array}\right] \quad[\mu]=\left[\begin{array}{c}
840 \\
557 \\
795 \\
840 \\
363 \\
157 \\
534 \\
230 \\
974 \\
967 \\
960
\end{array}\right]
$$

Following a well known procedure (Montgomery, 1991), first order model is obtained. The corresponding analysis of variance is shown in Table 4.

Table 4 - ANOVA for first order model

\begin{tabular}{|l|l|l|l|l|l|}
\hline Variation source & \multicolumn{1}{|c|}{ SS } & \multicolumn{1}{c|}{ df } & \multicolumn{1}{|c|}{ MSS } & \multicolumn{1}{c|}{ F test } & p-value \\
\hline $\mathrm{X}_{1}$ & 69938 & 1 & 69938 & 1427 & 0.0007 \\
\hline $\mathrm{X}_{2}$ & 29040.5 & 1 & 29040.5 & 593 & 0.0017 \\
\hline $\mathrm{X}_{3}$ & 381938 & 1 & 381938 & 7795 & 0.0001 \\
\hline $\mathrm{X}_{1} \mathrm{X}_{2}$ & 6612.5 & 1 & 6612.5 & 135 & 0.0073 \\
\hline $\mathrm{X}_{1} \mathrm{X}_{3}$ & 9248 & 1 & 9248 & 189 & 0.0053 \\
\hline $\mathrm{X}_{1} \mathrm{X}_{2} \mathrm{X}_{3}$ & 22684.5 & 1 & 22684.5 & 463 & 0.0022 \\
\hline Lack of fit & 398745.4 & 2 & 199372.7 & 4069 & 0.0002 \\
\hline Pure error & 98 & 2 & 49 & & \\
\hline Total (Corr) & 918304.9 & 10 & & & \\
\hline
\end{tabular}

After testing for coefficients significance at $\alpha=0.05$ level, the coded final model is:

$$
\mu=656-93 X_{1}+60 X_{2}-218 X_{3}+29 X_{1} X_{2}-34 X_{1} X_{3}-53 X_{1} X_{2} X_{3}
$$

A brief look to the relative magnitude of interactions coefficients, gives a clear evidence of pronounced curvature. As it can be observed, all interactions have values of the same order 
of individual factors. An analysis of variance, in this case, will show that the regression sum of squares is quite smaller than the total sum of squares and that there exists a large and, therefore, significative lack of fit in the model.

Of course, a curvature check is always possible. Thus,

$$
\text { Curvature Effect }=\left(\bar{y}_{2}-\bar{y}_{1}\right) \pm t_{(\alpha, v)} S_{\exp }
$$

$\bar{y}_{1}=$ average of the $\mathrm{n}_{1}$ experimental responses of the design (here $\mathrm{n}_{1}=8$ and $\bar{y}_{1}=539.5$ )

$\bar{y}_{2}=$ average of the $\mathrm{n}_{2}$ center points (here $\mathrm{n}_{2}=3$ and $\bar{y}_{2}=967$ )

$\mathrm{t}=$ student statistic (two tailed's test)

$\alpha=$ significance level $=0.05$

$\mathrm{v}=$ degrees of freedom of $S_{\text {exp }}($ here $\mathrm{v}=2)$

$S_{\text {exp }}=$ standard deviation of pure error (here $S=7$ ), and so

Curvature Effect $=(967-539.5) \pm \mathrm{t}_{(0.05,2)}(7)=427.5 \pm 4.3$. (7) $=427 \pm 30$

This result shows that responses at the center points are well higher than those belonging to the base design points and constitute a quantitative proof of curvature.

A closer look to the obtained model shows that factor $\mathrm{X}_{3}$ (liquid-solid ratio) should work at the lowest level in order to obtain greater viscosities. Figure 4, shows response surface for a fixed $X_{3}=-1$ level. It is clearly seen, that viscosity reaches a so called saddle point, that can't be described completely by the so far obtained model.

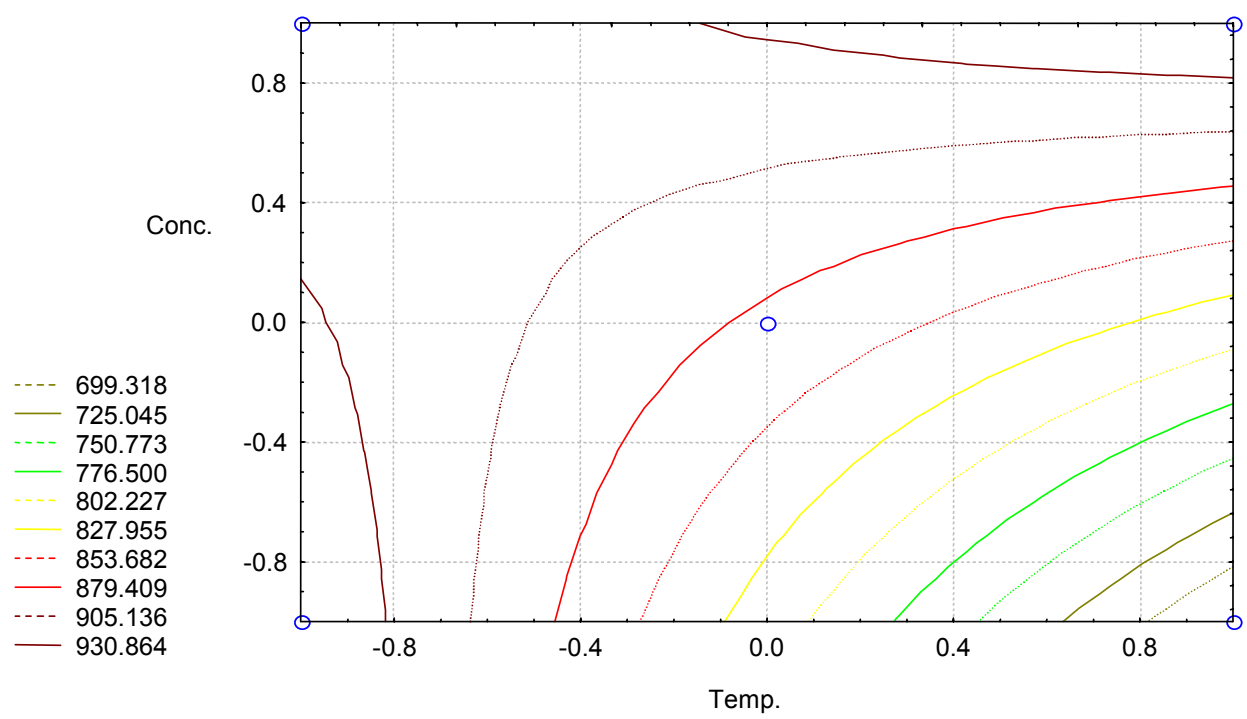

Figure 4 - Response Surface for Viscosity Behavior at X3 $=-1$ (First order model)

On the other hand, if $\mathrm{X}_{3}$ is held constant at +1 level Figure 5 shows a different situation, in which a plane with some curvature can be appreciated. 


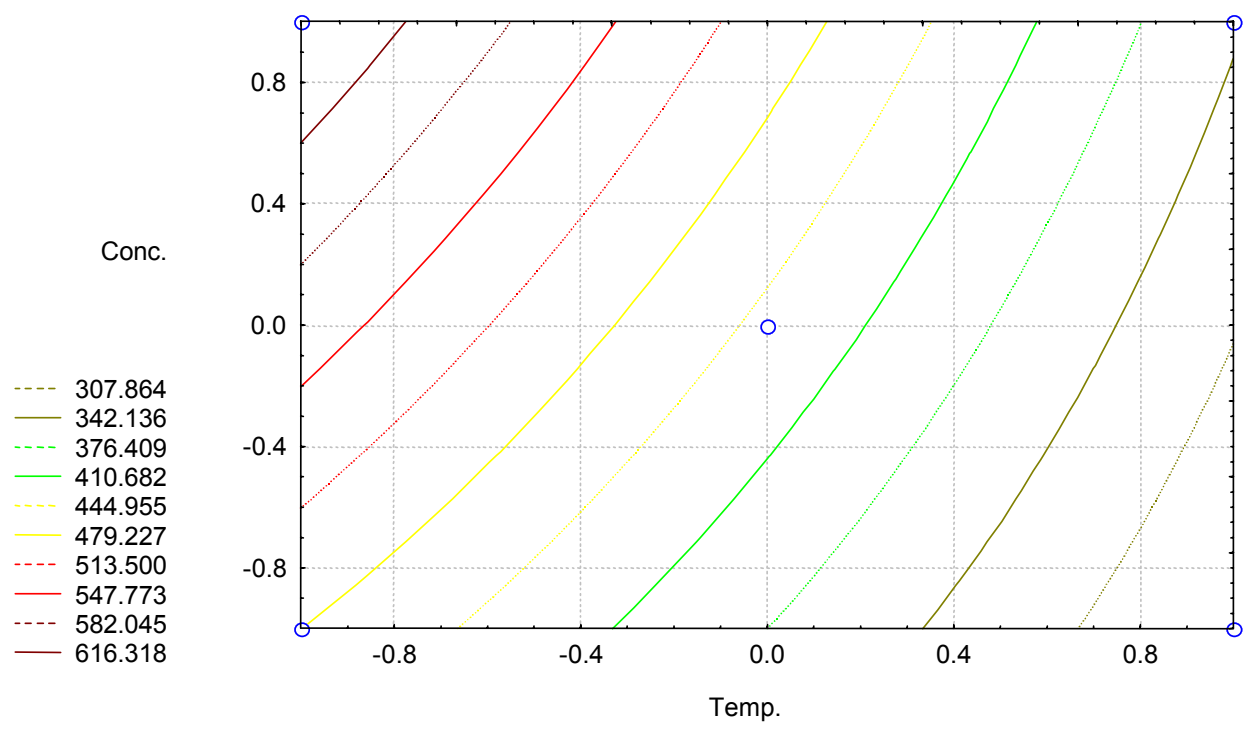

Figure 5 - Response Surface for Viscosity Behavior at X3 $=+1$ (First order model)

A tridimensional picture of both cases is given in Figure 6 and 7. In this particular case, a lowering of the liquid-solid ratio $\left(\mathrm{X}_{3}\right)$ should have it's limits because otherwise power increase due to stirring could be too high. Also, a point may be attained where very little or no liquid exits. This is, of course, a hypothetical situation, but helps to make a reasonable appreciation of how to change factor's levels.

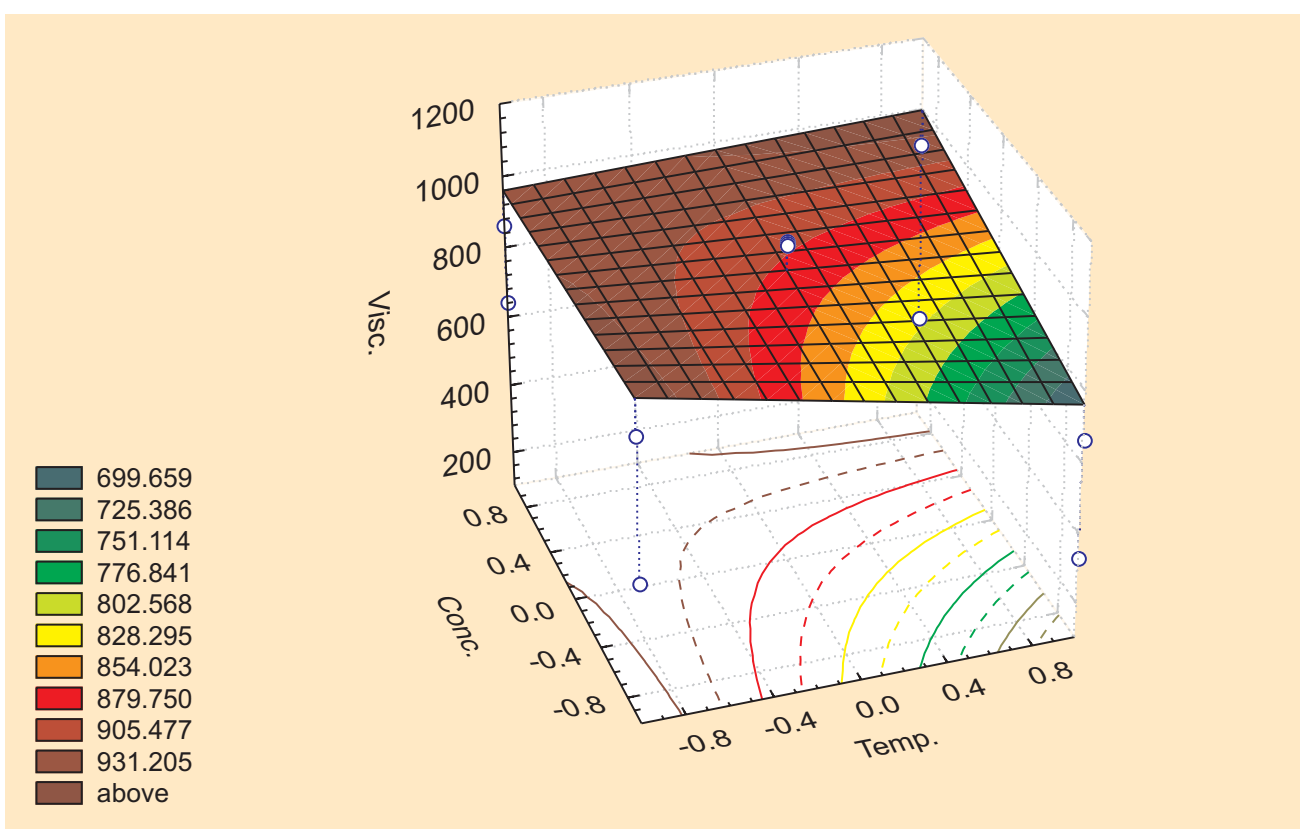

Figure 6 - Tridimensional picture of first order model for X3 $=-1$ 


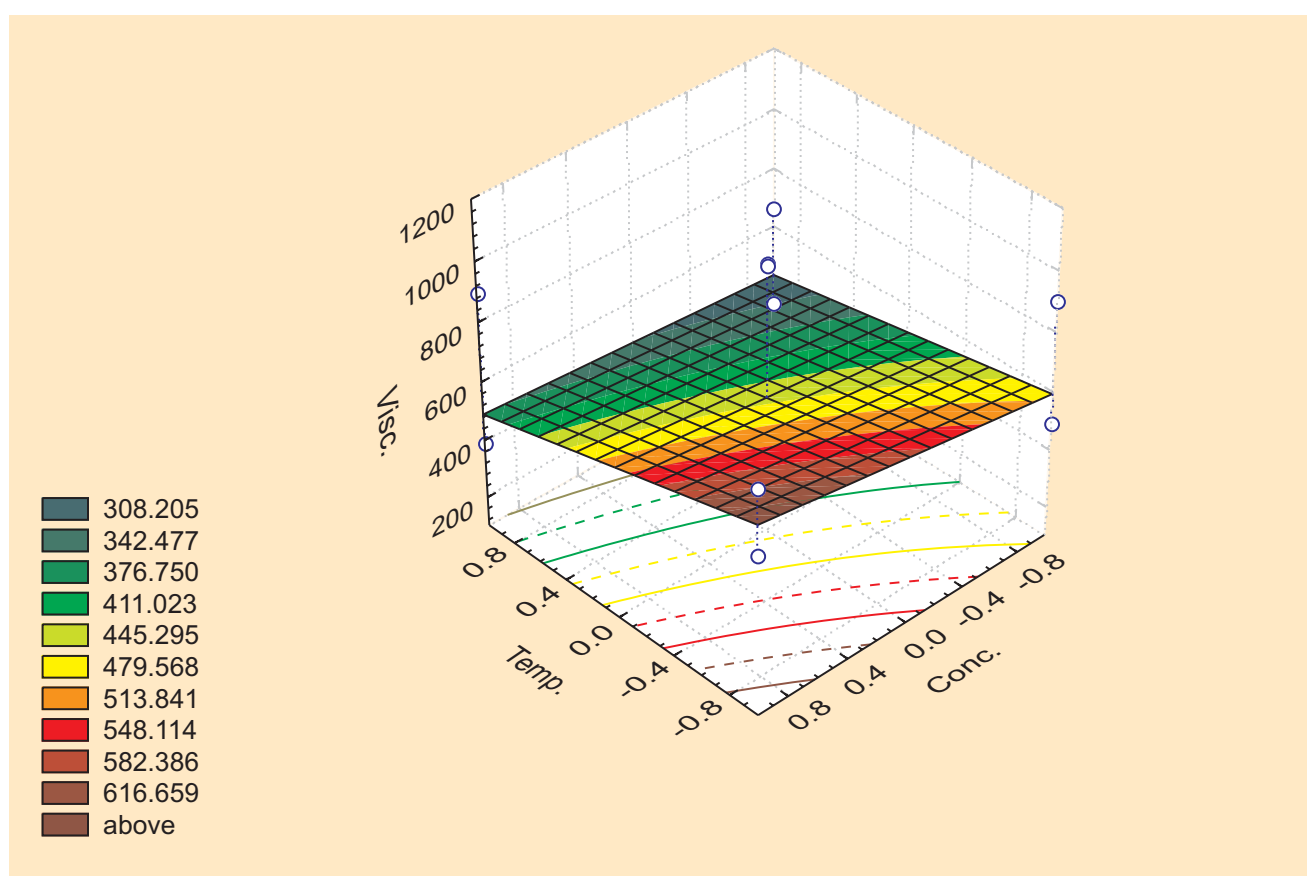

Figure 7 - Tridimensional picture of first order model for $\mathrm{X} 3=+1$

According to the SEROP scheme, it is recommended now to adjust a second order model due to the fact that the lineal model does not describe adequately viscosity behavior.

\subsection{Adjustment of a second order model (Montgomery, 1991)}

As there were evidences of a maximum in the vicinity of the initially studied experimental region, a CCOD was tried, making use of former $2^{3}$ full factorial as nucleus of the new design and performing 6 new experiments for the axial points $(\alpha=1.215)$. An additional center point is also added in order to improve $S_{\exp }^{2}$ precision, although three of them are already done. The corresponding experimental matrix as well as the response matrix are: 


$$
[X]=\left[\begin{array}{ccc}
X_{1} & X_{2} & X_{3} \\
-1 & -1 & -1 \\
+1 & -1 & -1 \\
-1 & +1 & -1 \\
+1 & +1 & -1 \\
-1 & -1 & +1 \\
+1 & -1 & +1 \\
-1 & +1 & +1 \\
+1 & +1 & +1 \\
-1.215 & 0 & 0 \\
1.215 & 0 & 0 \\
0 & -1.215 & 0 \\
0 & 1.215 & 0 \\
0 & 0 & -1.215 \\
0 & 0 & 1.215 \\
0 & 0 & 0 \\
0 & 0 & 0 \\
0 & 0 & 0 \\
0 & 0 & 0
\end{array}\right] \quad[\mu]=\left[\begin{array}{c}
840 \\
557 \\
795 \\
840 \\
363 \\
323 \\
157 \\
534 \\
230 \\
520 \\
555 \\
1617 \\
1081 \\
974 \\
967 \\
960 \\
961
\end{array}\right]
$$

After obtaining a second order model, ANOVA is conducted (Table 5).

Table 5 - ANOVA for second order model

\begin{tabular}{|l|l|l|l|l|l|}
\hline $\begin{array}{c}\text { Variation } \\
\text { source }\end{array}$ & \multicolumn{1}{|c|}{ SS } & \multicolumn{1}{c|}{ df } & \multicolumn{1}{|c|}{ MSS } & \multicolumn{1}{c|}{ F test } & p-value \\
\hline $\mathrm{X}_{1}$ & 93894 & 1 & 93894 & 2253 & 0.0000 \\
\hline $\mathrm{X}_{2}$ & 38105 & 1 & 38105 & 915 & 0.0001 \\
\hline $\mathrm{X}_{3}$ & 525577 & 1 & 525577 & 12614 & 0.0000 \\
\hline $\mathrm{X}_{1} \mathrm{X}_{2}$ & 6613 & 1 & 6613 & 159 & 0.0011 \\
\hline $\mathrm{X}_{1} \mathrm{X}_{3}$ & 9248 & 1 & 9248 & 222 & 0.0007 \\
\hline $\mathrm{X}_{1} \mathrm{X}_{2} \mathrm{X}_{3}$ & 22685 & 1 & 22685 & 544 & 0.0002 \\
\hline$X_{1}^{2}$ & 677441 & 1 & 677441 & 16259 & 0.0006 \\
\hline$X_{2}^{2}$ & 544965 & 1 & 544965 & 13079 & 0.0000 \\
\hline$X_{3}^{2}$ & 349098 & 1 & 349098 & 8378 & 0.0000 \\
\hline Lack of fit & 87 & 5 & 17 & 0.42 & 0.8164 \\
\hline Pure error & 125 & 3 & 42 & & \\
\hline Total (Corr) & 2259454 & 17 & \multicolumn{2}{|l}{$\mathrm{R}^{2}$ (adjusted df) $=0.99$} & \\
\hline
\end{tabular}


The final coded model, after significance tests for the coefficients and a lack of fit test for the model are done, is:

$\mu=966-93 X_{1}+59 X_{2}-219 X_{3}+29 X_{1} X_{2}-34 X_{1} X_{3}-53 X_{1} X_{2} X_{3}-361 X_{1}^{2}-324 X_{2}^{2}+259 X_{3}^{2}$

\subsection{Analysis of response's surfaces}

If in former model $\mathrm{X}_{3}$ is fixed at -1 level, following model is obtained:

Model 1: $\left(\mathrm{X}_{3}=-1\right)$

$$
\mu=1444-59 X_{1}+59 X_{2}+782 X_{1} X_{2}-361 X_{1}^{2}-324 X_{2}^{2}
$$

357.286

466.545

575.804

685.063

794.321

903.580

1012.839

1122.097

1231.356

1340.615

above

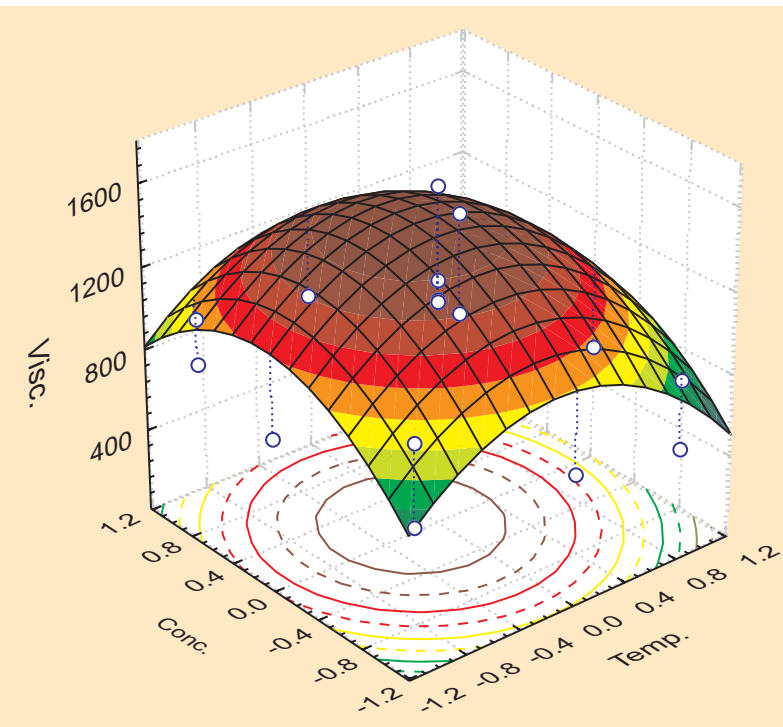

Figure 8 - Response Surface for Viscosity Behavior (Second Order model for X3 = -1)

Now, holding $X_{3}$ at +1 level, a new model can be shown:

Model 2: When $\mathrm{X}_{3}=+1$

$$
\mu=1006-1267 X_{1}+59 X_{2}-24 X_{1} X_{2}-361 X_{1}^{2}-324 X_{2}^{2}
$$




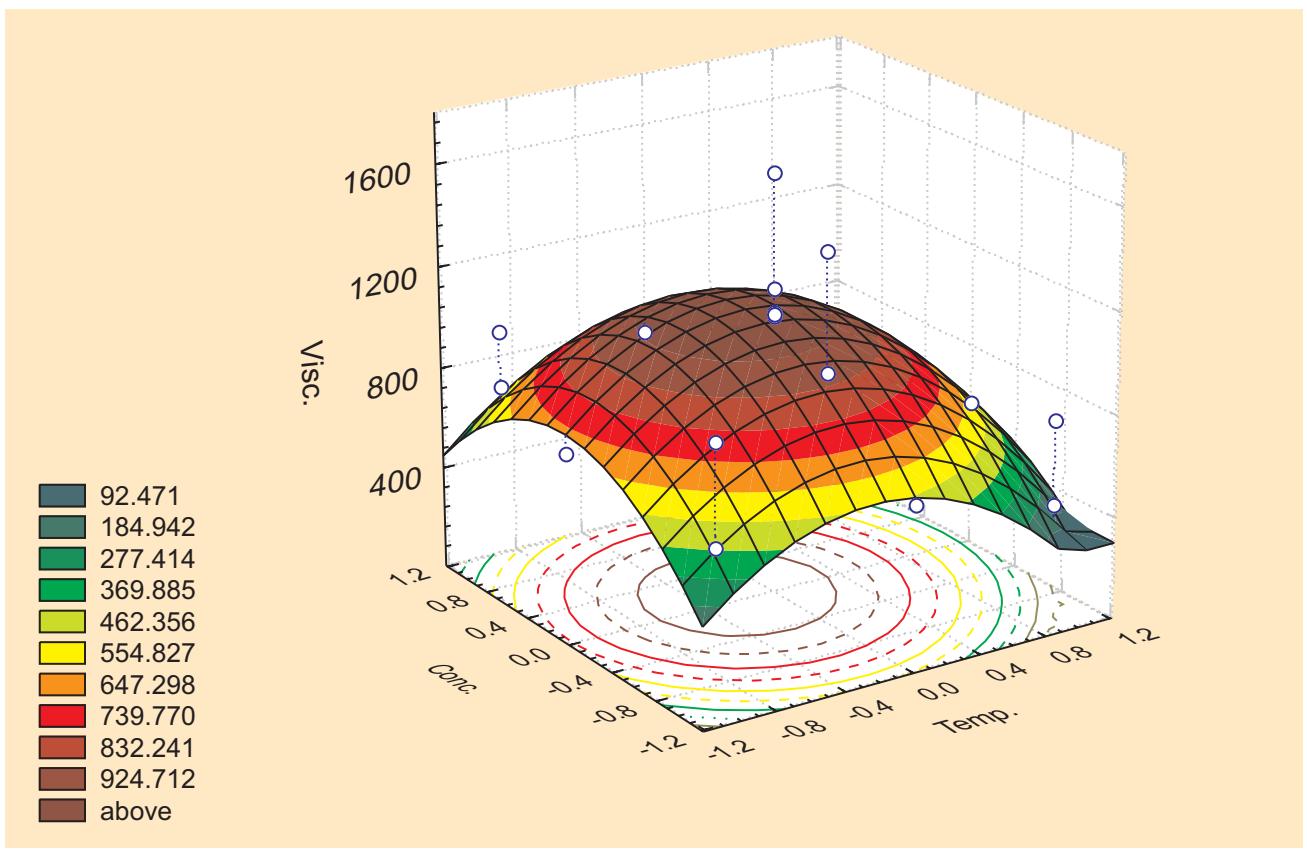

Figure 9 - Response Surface for Viscosity Behavior (Second Order model for X3 = +1)

Response's surfaces for both models are presented in Figure 7.

Both maximum points are conditioned by the values assigned to $\mathrm{X}_{3}$ and as expected are quite different.

\subsection{Determination of the optimum point}

In order to obtain the coordinates of the stationary point $\frac{\partial \mu}{\partial \chi_{i}}=0$ (i being 1 and 2 ) are determined for each model and from the solution of both equation systems, the conditional maximum coordinates are obtained. Thus, for model $1\left(\mathrm{X}_{3}=-1\right)$, maximum viscosity is reached at:

$\mathrm{X}_{1}$ : $\quad$ Temperature $=44^{\circ} \mathrm{C}$

$\mathrm{X}_{2}: \quad \mathrm{Na}_{2} \mathrm{CO}_{3}$ mass concentration $=1.036 \mathrm{~g} / \mathrm{L}$

$\mathrm{X}_{3}$ : $\quad$ Liquid-solid mass ratio $=10 \mathrm{~kg} / \mathrm{kg}$

$\mu_{\mathrm{opt}}=$ Maximum viscosity $=1449 \mathrm{mPa} . \mathrm{s}$

For model $2\left(\mathrm{X}_{3}=+1\right)$, optimum conditions are given when:

$\mathrm{X}_{1}: \quad$ Temperature $=42^{\circ} \mathrm{C}$

$\mathrm{X}_{2}: \quad \mathrm{Na}_{2} \mathrm{CO}_{3}$ mass concentration $=1.04 \mathrm{~g} / \mathrm{L}$

$\mathrm{X}_{3}$ : $\quad$ Liquid-solid mass ratio $=20 \mathrm{~kg} / \mathrm{kg}$

$\mu_{\text {opt }}=1015 \mathrm{mPa} . \mathrm{s}$

Due to practical reasons (values of $\mathrm{X}_{3}$ below $10 \mathrm{~kg} / \mathrm{kg}$ were not recommended), model 1 was taken as the final model. 


\section{Conclusions}

The SEROP is composed of a series of steps applicable to experimental regions in which only one stationary or optimum point exists and where all the involved factors or independent variables can be controlled. The number of necessary steps to reach the stationary point will depend in a great measure on the previous knowledge of the problem. The more knowledge of the nature of the investigated process, the less stages will have to be carried out. The presented general scheme shows a common sense way of dealing with these situations, looking for faster, cheaper and rigorous experimental procedures of research, based on an empirical approach.

\section{Acknowledgements}

The authors thank the State of São Paulo Research Foundation-FAPESP for the financial support, which made this publication possible.

\section{Nomenclature}

CCOD Central composed orthogonal designs

CCRD Central composed rotational designs

SEROP Strategy of empirical research and optimization process

$\mathrm{k} \quad$ Number of factors

$\mathrm{n}_{1} \quad$ Number of experimental responses of the fractional design

$\mathrm{n}_{2} \quad$ Number of responses at the center of the design

$S_{\exp }^{2} \quad$ Pure error

$\mathrm{t} \quad$ Student statistic

$\mathrm{X}_{\mathrm{i}} \quad$ Factor or independent variable $\mathrm{i}$

[X] Independent variable matrix

$\bar{y}_{1} \quad$ Average of $\mathrm{n}_{1}$ responses

$\bar{y}_{2} \quad$ Average of $\mathrm{n}_{2}$ responses

$\alpha$ Distance from the zero point of a factor's axis in CCOD and CCRD. Also significance level

$v \quad$ Degrees of freedom of $S_{\exp }^{2}$

$\mu \quad$ Viscosity (mPa.s)

$[\mu] \quad$ Responses matrix for viscosity

$\frac{\partial \mu}{\partial X_{i}} \quad$ Partial derivative of $\mu$ in respect to $X_{\mathrm{i}}$

SS Sum of squares

MSS Medium sum of squares

F -test-Fischer test

df . Degrees of freedom 


\section{References}

(1) Barros Neto, B.; Scarminio, I.S. \& Bruns, R.E. (1995). Planejamento e Otimização de Experimentos, Ed. UNICAMP, Campinas, Brazil.

(2) Box, G.E.P.; Hunter W. \& Hunter G. (1993). Estadistica para Investigadores. Introducción al diseño de experimentos, análisis de datos y construcción de modelos. Ed. Reverté S.A., Spain.

(3) Guerra Debén, J. \& Sevilla, E. (1988). Introducción al análisis estadístico para processos. Ed. Pueblo y Educación, Habana, Cuba.

(4) Haaland, P.D. (1989). Experimental design in biotechnology. Ed. Marcel Dekker Inc.

(5) López Planes, R. (1988). Diseño Estadístico de Experimentos. Ed. Científico Técnica, La Habana, Cuba.

(6) Mesa Pérez, J.M.; Valle, M. \& Guerrero, J.R. (1998). Optimización de la etapa de extracción de Alginato de Sodio (accepted for publication in Revista Tecnologia Química, Universidad de Oriente, Santiago de Cuba, Cuba, 18(2), 17-26).

(7) Montgomery, D.C. (1991). Design and analysis of experiments. Ed. John Wiley, New York, USA.

(8) Sutton, N.L. (1997). Variables Search: A simple technique. Chemical Engineering, 104(8), 106-109. 